\title{
Pseudomixoma peritoneal
}

\author{
Pseudomyxoma peritonei
}

\author{
Martha Cristina Sánchez Silva, * Fernando Morales Pérez ${ }^{\ddagger}$ \\ Citar como: Sánchez SMC, Morales PF. Pseudomixoma peritoneal. Acta Med. 2021; 19 (1): 134-135. https://dx.doi.org/10.35366/98586
}

Paciente femenino de 62 años de edad, antecedente de hernioplastia umbilical hace 12 años, cesárea hace 38 y 35 años respectivamente. Padecimiento actual: presenta dolor abdominal de tres meses de evolución, intermitente, tipo punzante localizado en hipocondrio izquierdo con aumento de intensidad en los últimos dos días, por lo que acude a consulta de cirugía general. Al momento de la valoración con dolor al toser, dolor en hipocondrio izquierdo con irradiación a epigastrio y tórax, niega pérdida de peso. A la exploración física se detecta hernia de pared anteromedial supraumbilical y dolor a la palpación del abdomen, se observa abdomen globoso por panículo adiposo, peristalsis presente. Se palpa masa supraumbilical izquierda, y dolor en hipocondrio izquierdo con irradiación a epigastrio.

Se le solicitó una tomografía computarizada de abdomen en fase simple y contrastada; se encontró una lesión ovoidea, heterogénea a expensas de zonas hipodensas que alternaban con otras de mayor densidad, mostrando atenuación grasa dependiente del peritoneo que infiltraba y causaba festoneado del bazo, la lesión midió $29.1 \times 14.2$ $\times 27.3 \mathrm{~cm}$ (Figura 1). Tras la aplicación del medio de contraste se mostró reforzamiento heterogéneo con dilatación y tortuosidad de los vasos, esta masa causaba desplazamiento medial, caudal y ventral del riñón izquierdo, lateral y anterior del páncreas así como lateral del duodeno (Figura 2). Se realizó el diagnóstico de pseudomixoma peritoneal por tomografía. La paciente fue trasladada a un hospital de tercer nivel para su manejo.

El pseudomixoma peritoneal es una enfermedad infrecuente ${ }^{1,2}$ con una presentación de dos casos por cada

\footnotetext{
* Médico adscrito de Hospital San Ángel Inn Sur.

‡ Médico adscrito de Grupo San Ángel Inn.
}

Correspondencia:

Martha Cristina Sánchez Silva

Correo electrónico: dramarthacristina@gmail.com

Aceptado: 20-02-2020.

www.medigraphic.com/actamedica
10,000 laparotomías ${ }^{1}$ y una incidencia de uno a tres casos en un millón cada año. ${ }^{2,3}$ Fue descrito por Cruveilhie en $1848^{3}$ y por Werth en $1884 .{ }^{4}$ Esta patología se caracteriza por acumulación de depósitos de tejido gelatinoso en la superficie del peritoneo ${ }^{1-3}$ secundaria a implante de un tumor primario adenomucinoso, principalmente dependiente del apéndice. ${ }^{4}$ También se asocia a tumores de ovario, peritoneo diafragmático, espacio retrohepático, correderas, hueco pélvico y epiplón. ${ }^{1}$ Suelen afectar más a mujeres que a hombres. ${ }^{3}$ La fisiopatología es controvertida, se considera que a medida que aumentan los niveles de mucina en el tumor primario, se produce ruptura y diseminación. ${ }^{2,4}$ Dependiendo la lesión primaria, se puede clasificar en dos, la primera en un pseudomixoma peritoneal con células benignas o limítrofes, no invade el estroma y se extiende por las superficies del peritoneo con buen pronóstico por su sensibilidad al tratamiento, es la presentación más frecuente, principalmente secundaria a ruptura de un mucocele apendicular. La segunda es una carcinomatosis peritoneal mucinosa secundaria a un tumor primario gastrointestinal agresivo o indiferenciado con mal pronóstico. ${ }^{3,5}$ La presentación clínica es variable y depende de la fase de la enfermedad, puede ser un hallazgo incidental en estudios de imagen o en laparotomías, presencia de dolor y distensión abdominal o tumoración palpable. En casos avanzados puede haber obstrucción intestinal y aumento de la circunferencia abdominal por ascitis. ${ }^{2,4}$ En las radiografías, en caso de ascitis, se observa aumento de la radiopacidad con escasa delimitación de órganos intraabdominales y en ocasiones presencia de calcificaciones. En ultrasonido se documenta líquido intraabdominal ecogénico, septado y desplazamiento secundario de asas intestinales. En tomografía se observa contenido mucinoso de baja densidad, puede haber áreas de mayor densidad por elementos sólidos o fibrosis. En signo de festoneado ${ }^{5}$ representa hendiduras en los márgenes capsulares de órganos intraperitoneales secundarias a presión extrínseca de los implantes mucinosos, este signo ayuda a diferenciar de una ascitis. Los órganos principalmente afectados son 
Figura 1:

Cortes axiales de tomografía de abdomen en fase simple (A) y contrastada (B). Lesión ovoidea, heterogénea con zonas hipodensas e hiperdensas, atenuación en rango de líquido, mide

$14.2 \times 29.1 \times 27.3 \mathrm{~cm}$, calcificaciones (flechas) y signo del festoneado con el bazo (puntas de flecha), líquido libre perihepático.
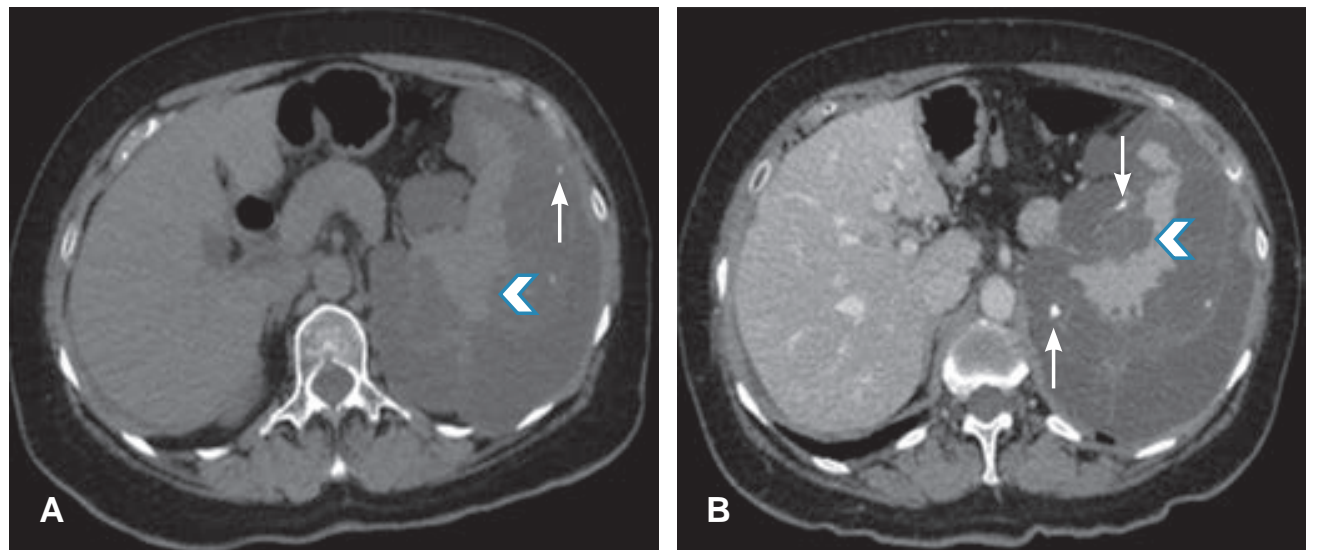
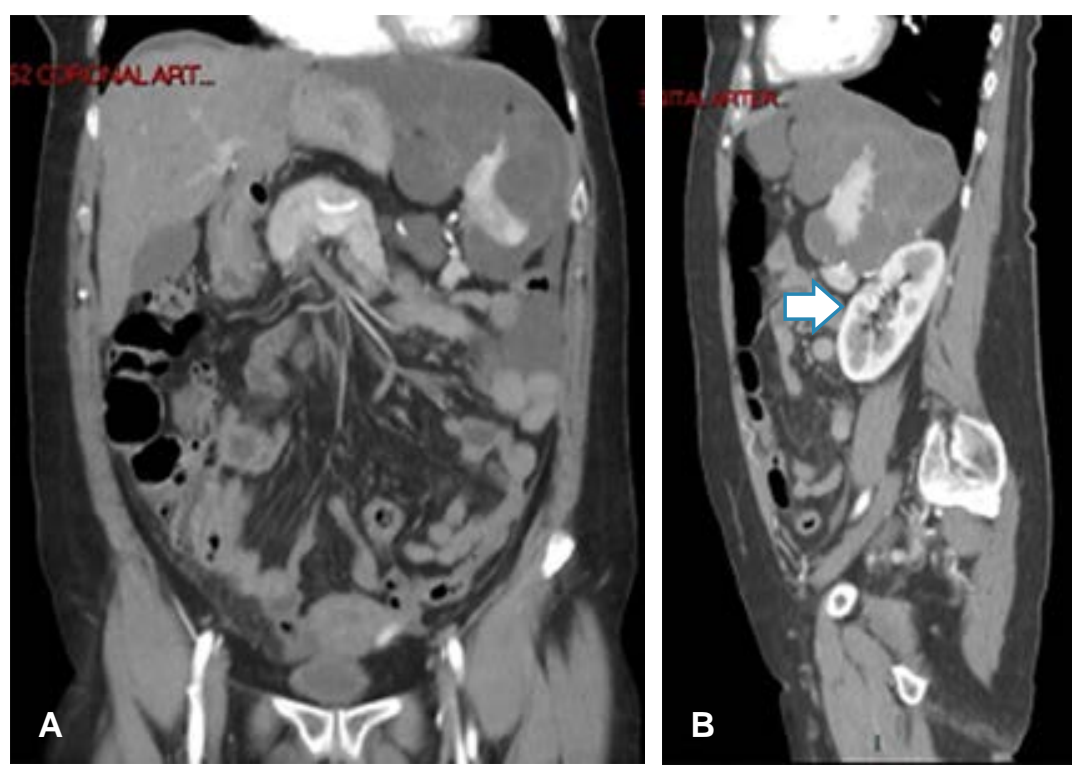

\section{Figura 2:}

Tomografía de abdomen con contraste intravenoso con reconstrucción de máxima intensidad de contraste. A) Corte coronal. B) Sagital. Líquido libre perihepático, periesplénico y en corredera parietocólica izquierda. Desplazamiento posterior del riñón izquierdo (flecha). hígado y bazo. En resonancia magnética, la mucina de los implantes peritoneales tiene baja señal en T1 y alta en T2. ${ }^{6}$ Se pueden observar implantes adyacentes a asas intestinales que condicionan oclusión. Los ovarios pueden tener metástasis quísticas complejas. El signo de festoneado y asas intestinales centralizadas o envueltas ayudan a diferenciar de una ascitis loculada. 5,6

\section{REFERENCIAS}

1. Suárez I, Reyna E. Pseudomixoma peritoneal. Rev Perú Ginecol Obstet. 2017; 63 (1): 97-101.
2. Syed AR, Wajahat S, Ravi S. Approach to pseudomyxoma peritonei. World J Gastrointest Surg. 2018; 10 (5): 49-56.

3. Penha D, Joao P, Paixao P, Rosado E, Cabral P, Guedes E et al. Pseudomyxoma Peritonei-What every radiologist should know. ESR. 2013: 1-19.

4. Carranza-Martínez I, Cornejo-López G, Monroy-Argumedo M, Villanueva-Sáenz E. Pseudomixoma peritoneal. Reporte de dos casos. Cir Cir. 2014; 82: 206-2011.

5. Levy AD, Shaw JC, Sobin LH. Secondary tumors and tumorlike lesions of the peritoneal cavity: imaging features with pathologic correlation. Radiographics. 2009; 29: 347-373.

6. Nougaret S, Nikolovski I, Paroder V, Vargas H, Sala E, Carrere S et al. MRI of tumors and tumor mimics in the female pelvis: anatomic pelvic space-based approach. RadioGraphics. 2019; 39: 1205-1229. 